\title{
How to Evaluate the Safety of a City
}

\author{
liying Liu ${ }^{1, \text { a }}$ \\ ${ }^{1}$ School of Electrical and Electric Engineering, North China Electric Power University, Beijing, \\ 102206, China \\ aliuliyingjiu@sina.com
}

Keywords: Evaluation Index System, Principal Level Analysis Model, Fuzzy Appraisal Model, AHP Method

\begin{abstract}
Contemporary countries, with the rapid development of technology, productivity and the rapid development of the society, is beginning the industrial society and information society evolution from industrial society. In this process, there have been serious class differentiation and conflict of interest, the type of crime is undergoing significant changes. Since the development of industrialization and city, violent crime is much higher than that of property crime. At the same time, with the advance of that, property crime has become the mainstream, and showed a sustained growth trend. Crime in the city is a major factor that threatens the urban safety. So it will be meaningful if an effective method can be developed to help evaluate how safe a city is. In this essay, create two math models to tackle this problem.

First of all, if we have some data of crime events, we can find out the related factors that affect the safety of the city based on the index system. Then a multi-level evaluation index system is formed, which consists of object layer, criterion layer and decision layer.

In model one, we set up a Principal Level Analysis Model in order to calculate the weights of various factors. Above all, we establish the judgment matrix of each element, according to the link between the elements, and figure out the value of this matrix. Then the weight value of each element in the criterion layer and decision layer is obtained by means of AHP Method.

In model two, we establish a Fuzzy Appraisal Model, which is an important approach to the quantitative analysis of city safety. To begin with, we set up evaluation sets, and then the subordinate degree of each index can be constructed. Finally, we calculate the comprehensive evaluation matrix, which can specify a measure of how safe this City is.
\end{abstract}

\section{Model One}

Analytic hierarchy process method was first proposed by the University of Pittsburgh operation scientist T. L. Saaty, a multi hierarchy analysis decision methods, it is set up based on the principle of system theory in the system level. It follows the nature of thing, decompose the complex problem into a number of orderly and systematic levels. In the stepwise analysis is simpler than the original level, and the subjective judgment is in the form of expression quantity. This is a relatively novel qualitative and quantitative analysis of the combination of multi factor evaluation method. Its characteristics are highly logical, systematic, concise and practical. It has been widely used in the decision analysis of the social economic system.

The basic principle of AHP is that , the study of complex problems is considered as a big system, through the analysis of the multiple factors of the system, calculating the factors interrelated ordered layer. Then ask experts to make objective judgment on each factor of each level, and give the importance of the corresponding quantitatively represented. Next, establish the mathematical model, to get the relative importance of each level of all factors and the weights, before sorting. 
Finally, according to the order, we can make planning and decision. Above all, the steps to apply this kind of methods are as follows :

1)Restore hierarchy. Gradually resolve the facing problem layer by layer, after that form a multi-layer structure.

2)Structure comparison judgment matrix. In the process of constructing comparative judgment matrix, we invite a number of experts or decision makers answer, to $A_{i}$ and ${ }^{A_{j}}$, which one is more important. Significantly, ${ }^{A_{i}}$ and ${ }^{A_{j}}$ belong to target layer $T$. Furthermore, professionals will also determine proportion criteria (diagram 4) endowed with the ratio of scale 1 to 9 . The judgment matrix $A=\left(a_{i j}\right)$ of the target layer $\mathrm{T}$ can be obtained. For that, judgment matrix $\mathrm{A}$ has the following properties: $\quad a_{i j}>0 ; a_{i j}=\frac{1}{a_{j i}}(i, j=1,2, \ldots, n)$. When there are $\mathrm{S}$ experts give comparison matrices, set $A^{(k)}=\left(a_{i j}\right)^{k}(k=1,2, \ldots, s)$, obtain geometric average of $a_{i j}^{(k)}$, and get pairwise comparison matrices $A=\left(a_{i j}\right)$.

Diagram1 proportion criteria [1]

\begin{tabular}{|l|l|l|l|l|l|}
\hline Scale value & 1 & 3 & 5 & 7 & 9 \\
\hline Importance & $\begin{array}{l}\text { Equally } \\
\text { important }\end{array}$ & $\begin{array}{l}\text { Slightly } \\
\text { important }\end{array}$ & $\begin{array}{l}\text { Obviously } \\
\text { important }\end{array}$ & $\begin{array}{l}\text { Strongly } \\
\text { important }\end{array}$ & $\begin{array}{l}\text { Absolutely } \\
\text { important }\end{array}$ \\
\hline \multicolumn{2}{|l|}{ 2,4,6,8 are intermediate values of adjacent judgments. } \\
\hline
\end{tabular}

Determine comparison matrix and conduct consistency test. Using MATLAB software to determine comparison matrix, eigenvector is obtained and consistency test is conducted. The normalization of each column of the judgment matrix is $a_{i j}{ }^{*}=\frac{a_{i j}}{\sum_{k=1}^{n} a_{k j}},(i, j=1,2, \ldots, n)$ . After, sum each row and set it as $\bar{W}_{i}=\sum_{j=1}^{n} a_{i j}^{*}$, and then normalize it to get the weight vector $\mathrm{W}$, which is the component of $\lambda_{\max }=\sum_{i=1}^{n} \frac{(A W)_{i}}{n W_{i}}$, At the same time, under the condition of eigenvalue is obtained. After all, conduct consistency test as follows: $C R=\frac{C I}{R I}<0.1, C I=\frac{\left(\lambda_{\max }-n\right)}{n-1}$. Among that, $\mathrm{n}$ is Index number, $\lambda_{\max }$ is eigenvalues of maximum of comparison matrix, and $R I$ is mean random consistency index (diagram 5) 
Diagram2 mean random consistency index $R I$

\begin{tabular}{|c|c|l|l|l|l|l|l|}
\hline $\begin{array}{c}\text { Matrix } \\
\text { order }\end{array}$ & 1 & 2 & 3 & 4 & 5 & 6 & 7 \\
\hline RI & 0 & 0 & 0.515 & 0.893 & 1.119 & 1.249 & 1.345 \\
\hline $\begin{array}{c}\text { Matrix } \\
\text { order }\end{array}$ & 8 & 9 & 10 & 11 & 12 & 13 & 140 \\
\hline RI & 1.420 & 1.462 & 1.487 & 1.516 & 1.541 & 1.558 & 1.580 \\
\hline
\end{tabular}

4)Compute the combination weighting of every layer element, and conduct consistency test. Taking advantage of the results of single ordering of all elements at the same level, the weight value of the importance of all the elements of this hierarchy is calculated for the upper layer. Then text consistency as the third step.

\section{Model Two}

Fuzzy comprehensive evaluation method is a comprehensive evaluation method based on fuzzy mathematics. The comprehensive evaluation method according to the membership degree of fuzzy mathematics theory converts qualitative evaluation into quantitative evaluation. In other words, fuzzy mathematics can make an overall evaluation of some objects determined by a variety of factors of things. It has clear results, characteristics of the system, and can better solve the problem fuzzy or difficult to quantify. In the same time, it is suitable for a variety of non- deterministic problems to solve.

The Second-Layer Fuzzy Comprehensive Evaluation Model is established by the following steps:[3]

Dive the set of factors $U=\left\{\mathrm{u}_{1}, \mathrm{u}_{2}, \ldots, \mathrm{u}_{\mathrm{n}}\right\}$ into $S$ sub-factor sets $\mathrm{U}_{1}, \mathrm{U}_{2}, \ldots, \mathrm{U}_{\mathrm{s}}$ according to a certain attribute, and $\mathrm{U}_{\mathrm{i}}=\left\{\mathrm{u}_{\mathrm{i} 1}, \mathrm{u}_{\mathrm{i} 2}, \ldots, \mathrm{u}_{\mathrm{in}_{\mathrm{i}}}\right\}(\mathrm{i}=1,2, \ldots, \mathrm{S})$. Also, it can satisfy the following conditions:

$$
\begin{gathered}
\text { I) } n_{1}+n_{2}+\ldots+n_{s}=n \\
\text { ii) } U_{1} \cup U_{2} \cup \ldots \cup U_{s}=U \\
\text { iii) } U_{i} \cap U_{j}=\Phi_{\text {for any }} i \neq j
\end{gathered}
$$

On each of the factors set $U_{i}$, respectively, make a comprehensive evaluation. Set $\mathrm{V}=\left\{\mathrm{v}_{1}, \mathrm{v}_{2}, \ldots, \mathrm{v}_{\mathrm{m}}\right\}$ as a set of reviews, in which the weights are assigned to each $\mathrm{V}_{\text {of }}$ the factors is $A_{i}=\left[a_{i 1}, a_{i 2}, \ldots, a_{i n_{4}}\right]$

Then we can get first order evaluation vector:

$$
\mathrm{B}_{\mathrm{i}}=\mathrm{A}_{\mathrm{i}} \times \tilde{\mathrm{R}}_{\mathrm{i}}=\left[\mathrm{b}_{\mathrm{i} 1}, \mathrm{~b}_{\mathrm{i} 2}, \ldots, \mathrm{b}_{\mathrm{im}}\right](\mathrm{i}=1,2, \ldots, \mathrm{s})
$$

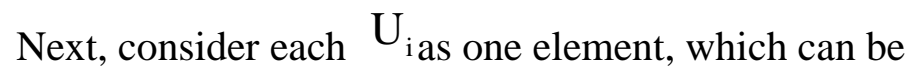




$$
\mathrm{K}=\left\{\tilde{\mathrm{u}}_{1}, \tilde{\mathrm{u}}_{2}, \ldots, \tilde{\mathrm{u}}_{\mathrm{s}}\right\}
$$

Therefore, $\mathrm{K}$ is another factor set, whose single factor evaluation matrix is as follows :

$$
R=\left[\begin{array}{c}
B_{1} \\
B_{2} \\
M \\
B_{s}
\end{array}\right]=\left[\begin{array}{cccc}
b_{11} & b_{12} & \ldots & b_{1 m} \\
b_{21} & b_{22} & \ldots & b_{2 m} \\
\ldots & \ldots & \ldots & \ldots \\
b_{s 1} & b_{s 2} & \ldots & b_{s m}
\end{array}\right]
$$

\section{Conclusion}

Take advantage of the above principle, we can get the comprehensive evaluation matrix of this city is $A=W_{1} \times R$ then we can compare the elements of $\mathrm{A}$ and the biggest one determines which grade the city safety belongs to.

\section{References}

[1] Si Shoukui, National Defense Industry Press, Mathematical modeling algorithm and application, 2011.

[2] Huang Shiguo, Research on Safety Management Assessment of Construction Enterprise Based on Fuzzy-AHP, 2009.

[3] Wu Lizhi, Mathematical model of urban fire risk assessment, 1994.

[4] Pan Mingming, Evaluation and Analysis of the Efficiency of Security Community Governance of Urumchi with Fuzzy Evaluation Method, 2012.

[5] Wei Yongzhong, On the warning level and the Index System of Urban Social Security Index, http://www.doc88.com/p-1062123208988.html,2007.

\section{通讯信息：}

\section{联系人高长青电话 13391797087}

\section{地址：山东省滨州市无棣小泊头镇南高村（顺丰、中通、申通）}

\section{邮编: 251900}

